\title{
A literatura, o sistema midiático e a emergência do quarto narrador
}

\author{
The literature, the media system and the emergence of the fourth narrator
}

\section{Demétrio de Azeredo Soster}

Universidade de Santa Cruz do Sul -UNISC - Santa Cruz do Sul - Rio Grande do Sul - Brasil

Resumo: Parte-se do pressuposto que os processos de enunciação não se estabelecem apenas no âmbito dos dispositivos e seus agentes, como sugeriram, na literatura e no jornalismo, respectivamente, Genette (1988) e Motta (2013). É possível identificá-los também a partir das operações do sistema midiático, que é formado pelos dispositivos jornalísticos (sites, redes sociais, jornais, revistas etc.), quando em rede. Nesta perspectiva, o sistema é detentor de uma voz narrativa; torna-se, assim, um "quarto narrador", de natureza multifacetada e plurivocal. Por se tratar de um objeto em movimento, que requer, no diálogo com Bergson (2005) e Marcondes Filho (2010), abordagem metodológica adequada, será identificado por meio da análise das marcas enunciativas que produz em seus movimentos. A reflexão será ilustrada por meio da análise de como se deu a repercussão midiática da narrativa literária Game of Thrones - A Guerra dos Tronos, de George Martin. A hipótese é que o quarto narrador, por realizar operações de natureza sistêmica, nos moldes de Luhmann (2009), não apenas reduz a complexidade de seus enunciados como transforma e é transformado nesta operação, reconfigurando toda uma ecologia midiática.

Palavras-chave: sistema, mídia, literatura, narrativa, jornalismo.

Abstract: This is on the assumption that the enunciation processes do not settle just within the devices and their agents, as suggested, in literature and journalism respectively Genette (1988) and Motta (2013). You can also identify them from the media system operations, which is formed by the journalistic devices (websites, social networks, newspapers, magazines etc.), when networking. In this perspective, the system holds a narrative voice; It becomes thus a "fourth speaker" plurivocal and multifaceted nature. Because it is a moving object, which requires, in dialogue with Bergson (2005) and Marcondes Filho (2010), adequate methodological approach will be identified by analyzing the enunciative marks that produces in his movements. The reflection will be illustrated through the analysis of how was the media impact of literary narrative Game of Thrones - Game of Thrones by George Martin. The hypothesis is that the fourth narrator, to conduct a systemic nature operations, along the lines of Luhmann (2009), not only reduces the complexity of their utterances as transforms and is transformed in this operation, reconfiguring an entire media ecology.

Keywords: system, media, literature, narrative, journalism. 


\section{Relações sistêmicas}

Move-nos a percepção que a emissão de vozes narrativas não ocorre apenas nos dispositivos e suas relações mais imediatas: são perceptíveis, também, no sistema em que estes dispositivos se inserem. Instaura-se, neste movimento, uma nova tessitura narrativa, que vamos chamar de quarto narrador. A constatação parte da visada original de Genette (1988) e Motta (2013), na literatura e no jornalismo, para quem as ofertas de sentido se dão (SOSTER, 2014, 2015) a) no âmbito do dispositivo e b) entre três extratos: primeiro, segundo e terceiro narradores, conforme veremos mais adiante.

Metodologicamente, iniciaremos observando como se estabelecem os primeiro, segundo, terceiro e quarto narradores. Em seguida realizaremos uma breve revisão bibliográfica a respeito da emergência do quarto narrador. Valer-nos-emos, para isso, também, das reflexões que temos realizado a respeito do assunto (SOSTER, 2014, 2015) e com o percurso de pesquisa do grupo Narrativas Comunicacionais Complexificadas, que coordenamos, e que é ligado, de um lado, ao Programa de Pós-graduação em Letras, enquanto que, de outro, ao Departamento de Comunicação da Universidade de Santa Cruz do Sul (Unisc). Em, seguida, analisaremos algumas estratégias narrativas utilizadas pelo quarto narrador, para, em seguida, encaminharmos as considerações interpretativas.

Como dito, Motta (2013) foi buscar em Gerard Genette (1988) os subsídios necessários para compreender como se estabeleciam as disputas de poder entre as vozes narrativas envolvidas nos processos jornalístico-comunicacionais. Resguardado o contexto original em que a transposição se deu, Motta (2013) aplicou o modelo ao jornalismo, pensando que, nele, o texto "(...) é produto de uma permanente e sutil negociação de interesses entre os veículos, os jornalistas e as fontes (posteriormente, personagens)" (MOTTA, 2013, p. 223).

Esta negociação, por sua vez, se dá pensando as organizações, por meio de seus dispositivos (uma empresa jornalística e o jornal que imprime, por exemplo), como narradores que têm ascendência tanto sobre os jornalistas como suas fontes, ambos igualmente narradores. São movimentos relacionais, é verdade; quem afeta também é afetado, mas há uma ascendência do primeiro narrador em relação aos demais extratos narrativos.

Visualmente, a partir de Motta (2013), e com base em trabalhos anteriores (SOSTER, 2014, 2015), podemos ilustrar a situação da seguinte forma:

Ilustração 01: Extratos narrativos

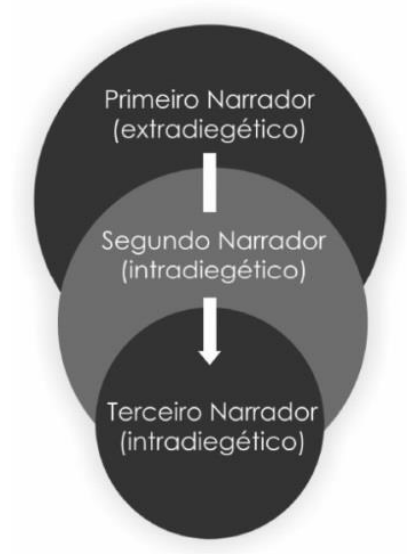

Fonte: Elaboração do autor

Vejamos cada um dos níveis narrativos isoladamente.

Primeiro narrador - Reconhecê-lo como tal implica observar que os relatos que nos chegam pela televisão, rádios, sites, jornais e revistas impressos, no que eles têm de jornalísticos, para ficarmos em alguns exemplos, são enunciados dos dispositivos a que se referem (a manchete do jornal, por exemplo), evidentemente, mas, também, das organizações e instituições que viabilizam os mesmos. Ou seja, o primeiro narrador, que é extradiegético, é, em sua essência, seminalmente plurivocal, à medida que é formado por agentes e processos dos mais diferentes matizes e naturezas (empresários, diretores, editores etc.).

Segundo narrador - "É o jornalista, a voz que enuncia propriamente a narração, organiza e costura a tessitura da intriga, dispõe as ações, conflitos, personagens e cenas." (MOTTA, 2013, p. 
228). O jornalista-narrador, que é intradiegético, possui autonomia operacional, mas suas ações estão condicionadas ao primeiro narrador. Por exemplo: o jornalista, mesmo tendo liberdade, em maior ou menos grau, de elaborar sua pauta, esta estará sempre umbilicalmente ligada ao local (dispositivo) em que ele vai publicá-la em seus mais diversos sentidos (espacial, temático, ideológico etc.)

Terceiro narrador - São as fontes, ou personagens, das matérias. Intradiegéticos, igualmente, porque dentro das histórias, e subordinados principalmente ao segundo narrador. Também aqui a percepção de que as fontes são subordinadas deve ser relativizada, à medida em que elas podem ter ascendência tanto sobre o segundo narrador como o primeiro. "(...) estes atores sociais passam muitas vezes a narrar como testemunhas, ganha status de personagens e voz ativa na história, transformando-se, em última instância, também em narradores" (MOTTA, 2013, p. 230).

\section{Quarto narrador}

Por este viés, ainda dialogando com 0 modelo de Motta (2013), para ficarmos na esfera comunicacional, enfrentamos dificuldades em compreender o sistema midiático, no que ele tem de jornalístico, ou não, como um narrador. Basicamente porque, reiterando, a visada circunscreve a análise dos processos de enunciação ao âmbito do dispositivo, seus agentes e relações. Não considera (e nem era sua intenção original, sublinhe-se), assim, a) a relação do dispositivo com os demais dispositivos, b) do dispositivo com o sistema em que se insere e, finalmente, c) com o ambiente em que o sistema se insere.

Observe-se, no entanto, que, em determinadas circunstâncias, como constatamos em nossa tese doutoral ${ }^{1}$ (SOSTER, 2009), certos acontecimentos têm a capacidade de $\operatorname{irritar}^{2}$ senão

\footnotetext{
1 Disponível em: [http://biblioteca.asav.org.br/vinculos/tede/DemetrioSosterComu nicacao.pdf ]Acesso em: [18 de setembro de 2015]

${ }^{2}$ É o nome que se dá, na teoria dos sistemas, à informação, que pode vir tanto do meio como os demais sistemas, e que é,
}

todo, parte do sistema midiático de forma mais ou menos abrangente, ou em intervalos muito curtos de tempo. À época, analisamos como dois acontecimentos diferenciados - a queda de um avião e denúncias de corrupção no campeonato brasileiro de futebol - não apenas irritavam, cada um a sua maneira, todo o sistema midiático como provocavam transformações substanciais nele e em seu entorno, afetando a própria natureza do acontecimento. Esta irritação, por sua vez, não apenas interfere na forma de ser dos dispositivos que compõe este sistema como, após uma sucessão de complexas operações internas, acaba sendo devolvida, na forma de informação, ao ambiente em que o sistema se insere. A estes processos de enunciação chamamos de vozes narrativas.

Vale lembrar que, na perspectiva na narratologia, vozes narrativas são fenômenos que abarcam pelo menos três instâncias da comunicação narrativa: 1) tempo em que a narração ocorre, 2) o nível narrativo (onde localizamos o narrador e o narratário, por exemplo) e 3) quem é o responsável pela narração.

(...) a voz tem a ver com um processo e com as circunstâncias em que ele se desenrola; o processo é o da enunciação narrativa, quer dizer, o ato da narração de onde decorre o discurso narrativo propriamente dito e a representação diegética que leva a cabo; as circunstâncias são as que envolvem este processo, circunstâncias de ordem temporal, material, psicológica etc. que condicionam o narrador de forma variável, projetando-se indiretamente sobre o discurso enunciado e afetando mais ou menos o narratário (LOPES \& REIS, 1988, p. 141).

Não se trata de dizer que pensar o sistema como um narrador tira do âmbito do dispositivo, e de seus níveis narrativos já identificados - primeiro, segundo e terceiro narradores, principalmente -, a capacidade de enunciação. É de suas operações que partem as enunciações. Mas de perceber, antes, que este conjunto de vozes alinhadas tematicamente dão forma, em seu conjunto, ao que chamamos de sistema midiático, e nos permitem identificá-lo como

o fim e ao cabo, a grande responsável pela transformação dos sistemas, que é sempre interna; que sempre parte de dentro. 
tal. Isso ocorre porque, ao fazê-lo, estabelecem diferenças em relação ao sistema em que se inserem e os demais sistemas, fortalecendo, dessa forma, sua própria identidade. E, em o fazendo, acabam por instaurar um novo nível narrativo, polissêmico e plurivocal, que não prescinde de sua instância primeira, o dispositivo, igualmente polissêmico e plurivocal, mas que é usualmente afeito a um lugar situacional - o dispositivo.

É importante salientar que movimentos desta natureza - a repercussão de um acontecimento por mais de um dispositivo do sistema midiático - não são novidades, no campo do jornalismo ou da comunicação como um todo: fazem parte de uma lógica processual que pode ser deflagrada por fatores tão distintos quando a intensidade de um acontecimento, seu ineditismo, impacto social, operações articuladas das organizações etc. O que muda é que também nesta instância torna-se possível identificar, como dissemos, processos de enunciação, ou seja, vozes narrativas.

A diferença, podemos afirmar, comparandose com o primeiro, segundo e terceiro narradores, é que o quarto narrador se estabelece, antes, em uma processualidade que em um lugar situacional. Mas, também, que ele reconfigura a geografia de forças que se estabelece entre os níveis narrativos, não sendo subordinado pelo primeiro narrador e dialogando relacionalmente com os demais níveis narrativos. A ilustração abaixo nos permite ilustrar melhor a situação.

\section{Ilustração 02: O quarto narrador}

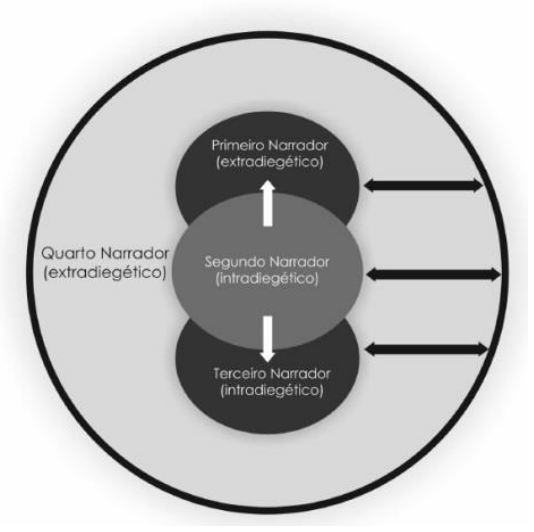

Fonte: Elaboração do autor
A título de revisão bibliográfica, estamos localizando nosso ponto de vista em um momento evolutivo em que, como dito a partir das palavras de Fausto Neto (2008), a sociedade aos poucos deixa de lado seu estatuto de sociedade dos meios para sociedade em vias de midiatização. Ou seja, um tempo evolutivo em que a tecnologia deixa sua condição de apêndice da sociedade para se tornar, ela própria, elemento estruturador desta (SOSTER, 2009), ao ponto de uma não poder ser pensada sem a outra.

Em capítulo de livro recente (2015), salientamos que a midiatização da sociedade dialoga estreitamente com a potencialização de uma ecologia midiática nos moldes de Neil Postman, Harold Innis, Marshall McLuhann. Ou de uma nova ambiência, que Sodré (2002) vai chamar de "quarto bios", a partir da categorização aristotélica ${ }^{3}$, e Gomes (2006), de "uma nova forma de ser no mundo". Hjarvard (2014), por sua vez, dirá que se trata da alteração de todo "um modo de ser da sociedade" a partir tanto de seu crescimento como da influência dos meios de comunicação que existem nesta.

Partindo deste ponto, e considerado que a midiatização pode ser compreendida, ainda, como o momento em que a sociedade passa a se valer de uma lógica midiática para estabelecer seus diálogos, observaremos, a seguir, como se estabeçece o quarto narrador por meio da análise da repercussão da narrativa literária Game of Thrones - A Guerra dos Tronos, de George Martin.

\section{A guerra dos tronos}

Observar como o quarto narrador se manifesta, tendo como objeto de análise a narrativa Game of Thrones - A Guerra dos Tronos, de George Martin, implica considerar que ela se dá sobre uma espécie de reconfiguração a partir do momento em que é absorvida pelo sistema midiático. Ou seja, quando a narrativa, originalmente em formato de livro

\footnotetext{
${ }^{3} \mathrm{O}$ primeiro bios diz respeito à vida contemplativa; o segundo, à vida política; o terceiro, à vida prazerosa (SODRÉ, 2002, p. 25).
} 
impresso, passa a circular pelo sistema por meio de dispositivos tão diversos quanto sites, blogs etc, reconfigurando-se neste movimento. Emerge, destes processos de enunciação, uma espécie de novo sentido geral do texto em decorrência de movimentos de natureza sistêmica.

É neste lugar processual que localizamos a "voz", ou as "vozes" do quarto narrador. A percepção mais imediata, na comparação com o texto original, é que o quarto narrador busca, em seus relatos, reduzir a complexidade da narrativa, tornando-a relativamente linear, na comparação com o texto impresso. Compreender esta afirmação implica observar que os processos de enunciação do quarto narrador são decorrentes de operações de natureza sistêmica. Ou seja, autorreferenciais, no diálogo com Luhmann (2009). Em o sendo, seu objetivo primeiro é a redução da complexidade do sistema com dois propósitos: 1) garantir as operações do mesmo e 2) por meio da geração de diferenças, estabelecer tanto 2.1) identidade como 2.2) diferença. Em palavras mais simples, conforme havíamos observado em momentos anteriores (SOSTER, 2014, 2015) também aqui estamos falando de reconfigurações inerentes a movimentos que visam a manutenção do próprio sistema, neste caso o midiático.

Este movimento se verifica de forma mais visível quando a narrativa se transforma em seriado no canal de televisão HBO, em abril de 2011, produção de David Benioff e D. B. Weiss, sendo transmitida simultaneamente para mais de 170 países simultaneamente. O que, no papel impresso, era uma narrativa prolixa e, em muitos momentos, caótica, haja vista a exuberância de personagens, tramas e situações que envolve, passa a ser narrado em cinco temporadas; cada temporada contendo dez capítulos. Neles, de um lado, encontramos, claro, o diálogo temático com a obra original, mas, também, a preocupação de tornar a narrativa a mais coerente possível aos que lhe acessam são marcas identificáveis. Identificamos, aqui, uma estratégia narrativa por meio da qual Game of Thrones tanto pode ser facilmente compreendido por quem the acessa, à revelia das diferenças culturais, como, decorrência disso, amplia em muito seus limites de circulação. Ou seja, permite que o sistema viabilize suas operações.

É o que demonstrou, por exemplo, pesquisa envolvendo mais de mil pessoas ligadas de uma forma ou outra à narrativa quando perguntou sobre a forma, via dispositivo, que os entrevistados ficaram sabendo de Game of Thrones: 292 pessoas disseram que conheceram a partir da televisão, conta 206 a partir dos livros.

Gráfico 01: Formas de acesso via dispositivos

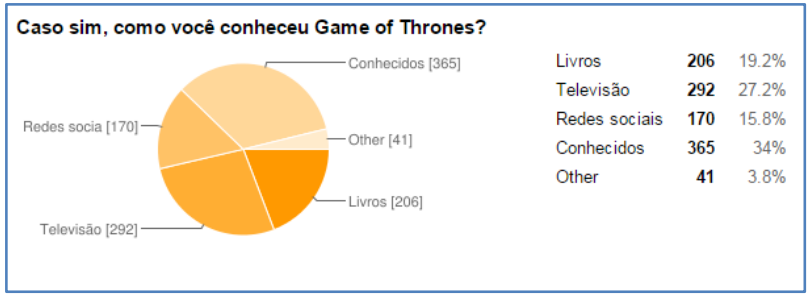

Fonte: Elaboração do autor

Mesmo que a existência da série tenha chegado a $34 \%$ dos entrevistados via "conhecidos", pode-se imaginar, em um exercício de livre interpretação, que, mesmo aqui, a reverberação se deu principalmente a partir dos filmes da série. A afirmação é corroborada no gráfico 2, quando foi perguntado se os entrevistados leram a obra. Observe-se que mais da metade $(50,3 \%$, ou 542 pessoas) não haviam lido, enquanto que 312 (28\%) somente parte da obra, contra apenas 209 (10,4\%) que haviam lido toda.

Gráfico 2: Quantidade de leitores

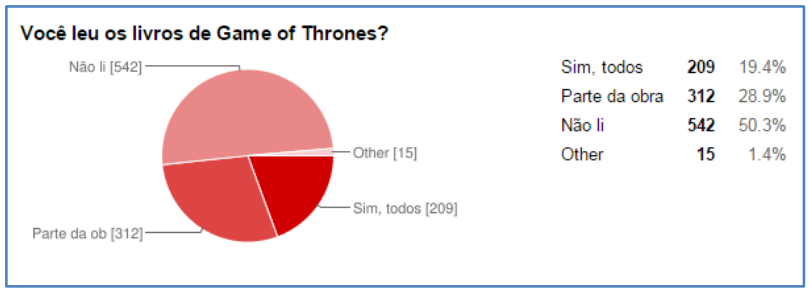

Fonte: Elaboração do autor 
As redes sociais cumpriram um papel semelhante às temporadas e capítulos da série, mas identicamos, nelas, um característica de natureza pedagógica, se comparadas aos filmes. Ou seja, mais que narrar, preocuparam-se em "explicar" e contextualizar a narrativa em seus mais diferentes aspectos, seja em termos de personagens ou situações, estabelecendo, desta forma, uma tessitura cognitiva muito específica. É o que ocorreu, por exemplo, com o Twitter. Cada personagem destacado pela série televisiva ganhou um perfil específico, como o de Tyrion Lennister ${ }^{4}$, abaixo:

Imagem 1: Perfil de Tyrion Lennister

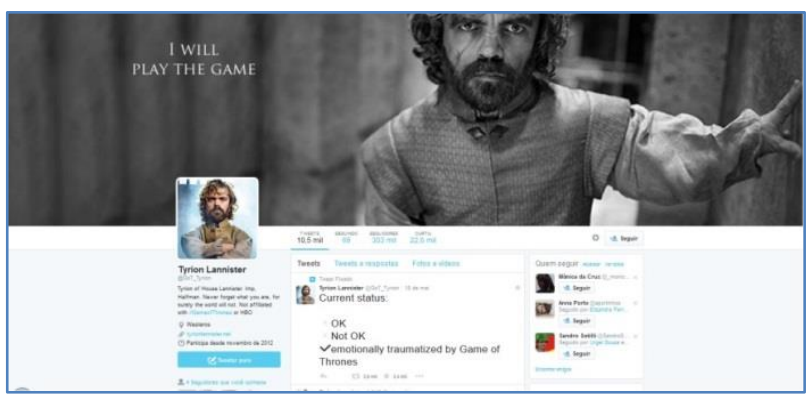

Fonte: Twitter

Importante salientar que os posts dos personagens de Game of Thrones no Twitter se referiam tanto ao que estava ocorrendo na narrativa como aos bastidores da produção.

O Facebook ${ }^{5}$ cumpriu um papel semelhante ao Twitter, mas mais focado no que estava ocorrendo durante os episódios. Cumpria, desta forma, um papel igualmente didático, no sentido de tornar compreensiva a narrativa, mas focada, principalmente, no na trama. Por meio dela, por exemplo, podia-se observar o estado de espíritos dos personagens, frases célebres, suas ambições e o papel que desempanhavam na narrativa, por exemplo.

\footnotetext{
${ }^{4}$ Disponível em: https://twitter.com/GoT Tyrion

${ }^{5}$ Disponível em:

$\underline{\text { https://www.facebook.com/GameofThronesBR?fref=nf }}$
}

Imagem 2: Foco no episódio

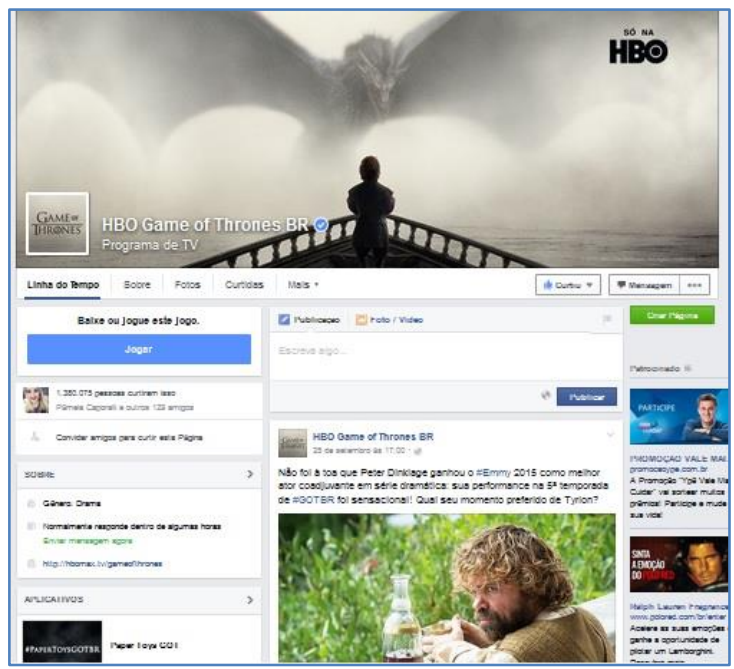

Fonte: Facebook

A Wikipédia ${ }^{6}$, por sua vez, em consonância com sua vocação enciclopédica, apresenta-se, por meio de seus verbetes e links neste contexto como uma importante referência a respeito dos inúmeros significados da série, como observamos nas imagens 3 e 4 - esta última ligada ao site oficial de Game of Thrones.

Imagem 3: Verbetes na rede 1

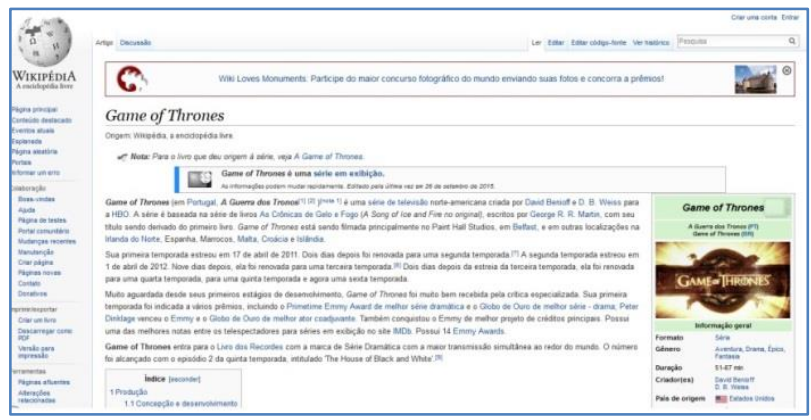

Fonte: Wikipédia

Imagem 4: Verbetes na rede 1

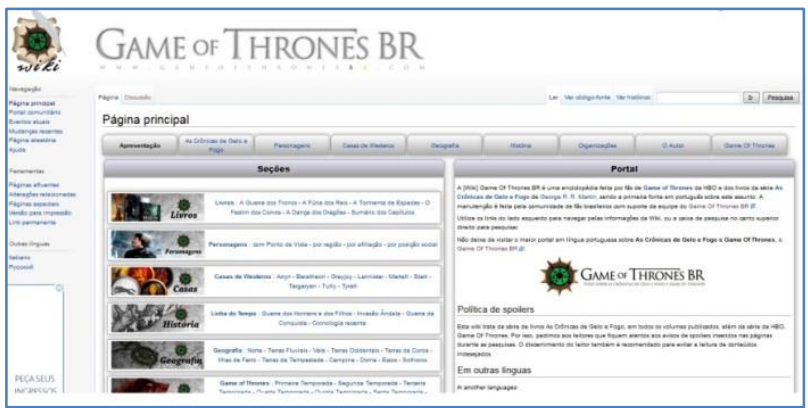

Fonte: Wikipédia

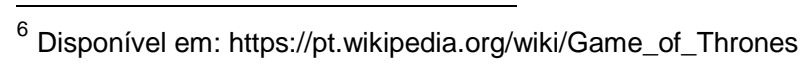

Signo [ISSN 1982-2014]. Santa Cruz do Sul, v. 41, n. nesp, p. 154-161, jan./jun. 2016. 
Não vamos nos alongar demais nos exemplos. Dois outros exemplos, no entanto, permitem-nos observar que os processos de enunciação dos dispositivos do sistema midiático não se limitaram ao universo imediato da série. É o caso, por exemplo, do infográfico ${ }^{7}$ publicado pelo site UOL (imagem 5), onde é feita uma descrição pormenorizada dos reinos que compreendem o universo de GOT:

Imagem 5: Infográfico

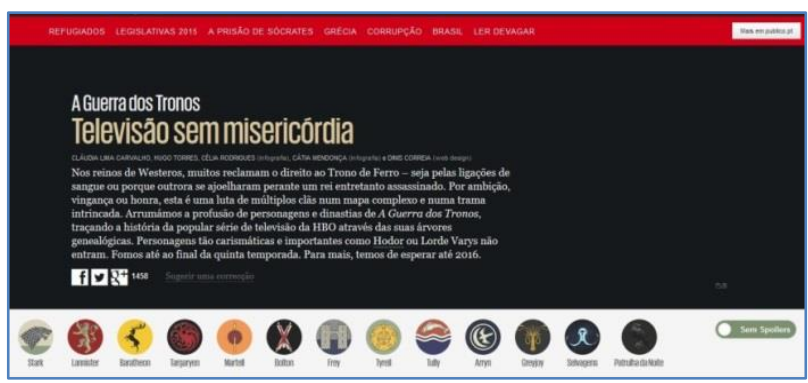

Fonte: $U O L$

Ou, ainda, de um infográfico veiculado no site do jornal norte-americano The Washington Post ${ }^{8}$ com propósitos semelhantes, mas focado no volume de mortes ocorridos ao longo de cada uma das temporadas da série.

Imagem 6: Infografia

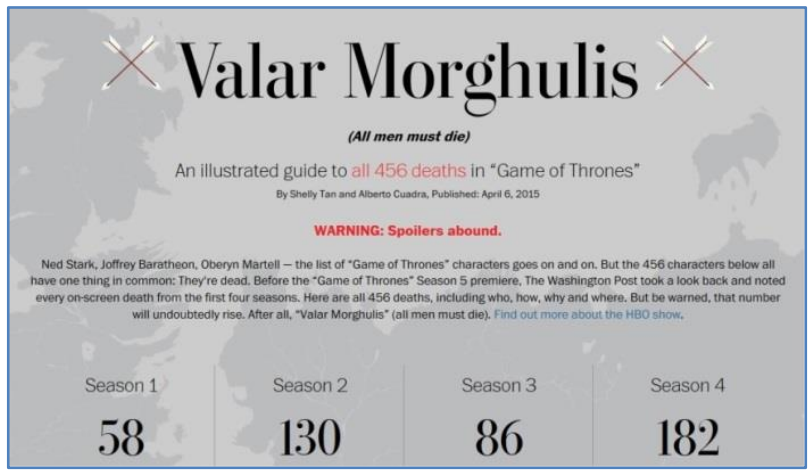

Fonte: The Washington Post

\footnotetext{
${ }^{7}$ Disponível em: http://publico.uol.com.br/culturaipsilon/voltamos-aos-sete-reinos ${ }^{8}$ Disponível em http://www.washingtonpost.com/graphics/entertainment/gameof-thrones/?fb ref=Default
}

Sobre este aspecto, a pesquisa referenciada anteriormente observou que as redes sociais foram utilizadas de forma acentuada pelas pessoas que acompanharam a série, como demonstra o gráfico 3, abaixo. Neles, 66,3\% dos entrevistados - 602 pessoas - disseram que acompanhavam a série pelo Facebook, e 5,8\% - 53 pessoas - pelo Twitter:

Gráfico 3: Modo de acompanhamento

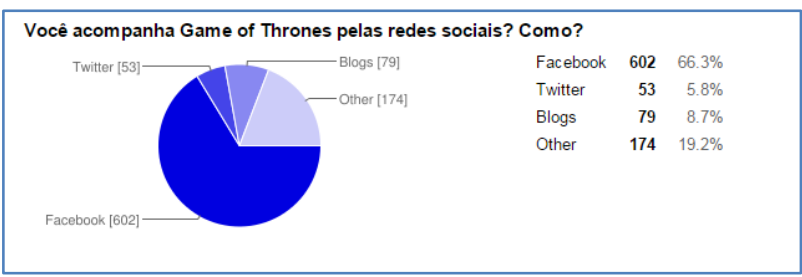

Fonte: Elaboração do autor

\section{Considerações interpretativas}

Compreender o que significa, àquele que analisa os processos de enunciação, a presença, no âmbito da narrativa, de um quarto extrato narrativo, implica considerar, em primeiro lugar, que novas gramáticas interpretativas são necessárias à tarefa. Principalmente porque o objeto de análise, que estamos chamando aqui de quarto narrador, é substancialmente distinto em sua estrutura dos objetos convencionais - um livro, por exemplo -, e isso se deve fundamentalmente ao fato de ele se personificar mais visivelmente quando em movimento. Neste sentido, dialogando com Bergson (2005), toda e qualquer tentativa de compreendê-lo pelas partes permitirá, antes, a compreensão da parte do que do conjunto em que ela se insere. Ou, na perspectiva de Bertalanffy (2013), a parte existe enquanto inserida em um sistema; ainda assim, sua condição de "parte" não traduz o sistema, apesar, como dissemos, de compô-lo e de este não poder ser pensado sem aquela.

Contudo, e foi isso que fizemos neste artigo, se observarmos as "partes" como índices da existência de níveis mais profundos de significação, e se evitarmos perspectivas totalizantes, acreditamos 
que, por meio delas, possamos ter uma compreensão, ainda que aproximada, do objeto a que nos referimos. Ao que observa, neste caso, cabe o papel de tradutor, ou intérprete, de uma determinada tessitura da experiência que emerge a partir, como dissemos, de pistas dispostas ao longo do objeto em análise.

É dizer, por outras palavras, que, pensar o quarto narrador a partir da reverberação midiática de Game of Thrones implica considerar que ele pode ser percebido a partir das marcas discursivas que emergem de seus mais distintos processos de enunciação, considerando-as a partir de sua intencionalidade. O que temos, por este viés, é, então, um conjunto de dispositivos buscando, individualmente e em seu conjunto, "simplificar" a narrativa, na comparação com a história original, como estratégia de persuasão. E, nesta busca, sendo reconhecido como estrato narrativo.

A lógica operacional, portanto, é sistêmica, nos moldes de Luhmann (2009), à medida que a redução da complexidade se estabelece como estratégia de viabilização das operações do próprio sistema, visando, com isso, como dissemos, tanto a geração de diferenças como de identidade. Neste caso, do quarto narrador.

\section{Referências}

BERGSON, Henri. A evolução criadora. São Paulo: Martins Fontes, 2005.

BERTALANFFY, Ludwig von. Teoria geral dos sistemas. Petrópolis: Vozes, 2013.

FAUSTO NETO, Antônio. Fragmentos de uma "analítica" da midiatização. MATRIZes, São Paulo. v. 1, n. 2, p. 89-105, abr. 2008.

GENETTE, Gerárd. Figuras III. Barcelona: Lumen, 1988.

GOMES, Pedro Gilberto. Filosofia e ética da comunicação na midiatização da sociedade. São Leopoldo: Unisinos, 2006.

HJARVARD, Stig. A midiatização da cultura e da sociedade. São Leopoldo: Unisinos, 2014.
LOPES, Ana Cristina M.; REIS, Carlos. (Org.) Dicionário de teoria narrativa. São Paulo: Ática, 1988.

LUHMANN, Niklas. Introdução à teoria dos sistemas. Rio de Janeiro: Vozes, 2009.

MARCONDES FILHO, Ciro. Nova teoria da comunicação. São Paulo: Paulus, 2010.

MOTTA, Luiz Gonzaga. Análise crítica da narrativa. Brasília: UnB, 2013.

SODRÉ, Muniz. Antropológica do espelho: uma teoria da comunicação linear e em rede. Petrópolis: Vozes, 2002.

SOSTER, Demétrio de Azeredo. O sistema como quarto narrador do jornalismo. In: TEMER, Ana Carolina Rocha Pessôa; SANTOS, Marli dos (Org). Fronteiras híbridas do jornalismo. Curitiba: Apris, 2015

Jornalismo e literatura: as complexificações narrativas jornalísticas de cunho biográfico. In: __. (Org.). Narrativas

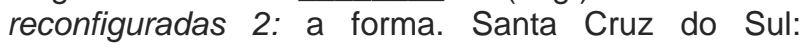
Edunisc, 2014.

O jornalismo em novos territórios conceituais: internet, midiatização e a reconfiguração dos sentidos midiáticos. 2009. 185 f. Tese (Doutorado em Ciências da Comunicação) - Universidade do Vale do Rio dos Sinos, São Leopoldo, 2009. 